\title{
Is low birth weight a risk factor for asthma during adolescence?
}

\author{
D S Seidman, A Laor, R Gale, D K Stevenson, Y L Danon
}

Department of Obstetrics and Gynecology,

Sheba Medical Center,

Tel-Hashomer 52621 .

Israel

D S Seidman

Medical Statistics

Branch,

Israeli Defence Force

Medical Corps

A Laor

Department of

Neonatology,

Bikur Cholim Hospital,

Jerusalem,

Israel

R Gale

Department of

Pediatrics,

Stanford University

School of Medicine,

Stanford,

California,

USA

D $\mathrm{K}$ Stevenson

Division of

Pediatric Immunology,

Belinson Medical Center,

Sackler School

of Medicine,

Tel-Aviv University,

Israel

Y L Danon

Correspondence to:

Dr Seidman.

Accepted 13 December 1990

\begin{abstract}
The effect of low birth weight on the incidence of asthma by 17 years of age was investigated by studying medical draft examination records of 20312 male subjects born in Jerusalem between January 1967 and December 1971. Additional information on birth weight and other demographic factors was abstracted from the Jerusalem Perinatal Study computerised database. A stepwise multiple logistic regression was used to estimate the odds ratios for developing asthma by 17 years of age in $500 \mathrm{~g}$ birthweight categories from $<2000 \mathrm{~g}$ to $4500 \mathrm{~g}$. The odds ratios were adjusted for the confounding effects of ethnic origin, social class (determined by area of residence), paternal education, maternal age, and birth order. The group with low birth weights $(<2500 \mathrm{~g}, \mathbf{n}=1004)$ had a significantly increased risk of developing asthma by 17 years of age, with an adjusted odds ratio of 1.44 (95\% confidence interval (CI) 0.79 to 2.66) for birthweight group $<2000 \mathrm{~g}$ and 1.49 (95\% CI 1.05 to 2.12 ) for birthweight group 2000-2499 g compared with the reference group of 3000-3499 g.

We conclude that infants with birth weights of $<2500 \mathrm{~g}$ may have a higher risk of asthma during childhood and adolescence than infants who were heavier at birth.
\end{abstract}

Advances in neonatal intensive care have greatly improved the survival of low birthweight (LBW) infants, but they still have a high risk of handicaps. ${ }^{12}$ Currently little is known about the long term respiratory outcome of LBW infants. Chan et al reported a close association between low birth weight and poor airway function, ${ }^{3}$ and troublesome cough at 7 years of age. ${ }^{4}$

The aim of this study was to evaluate the influence of low birth weight on the incidence of asthma during childhood and adolescence. The possible effects of social, ethnic, and environmental factors were taken into account.

\section{Subjects and methods}

The computerised records of the medical examinations of 20312 male recruits to the Israeli army who were born in Jerusalem between 1964 and 1971 were reviewed to establish the incidence of asthma. Each subject had been asked specifically whether he had ever been diagnosed as having asthma and whether he had ever had recurrent wheezing, nocturnal coughing, or coughing or wheezing after exertion
(I Auerbach, C Springer, S Godfrey, personal communication). All those with any symptoms that could have been indicative of past or present asthma were referred for a second examination by a pulmonologist. This examination included a further detailed history, physical examination, and spirometry while at rest. An exercise test was done during the latter period of our study in all subjects except those who had overt signs of obstruction on spirometry. The specific information about lung function information is not available, however, as the computerised data included only the final diagnosis.

Asthma was diagnosed only in cases with clear medical evidence of past or present bronchial disease, as opposed to episodic attacks. Birth weights recorded at the time of delivery were obtained from the computerised files of the Jerusalem Perinatal Study. ${ }^{56}$ Detailed demographic data were available from the computerised records of the military draft medical examination. ${ }^{7}$ The data for each individual were matched using a seven digit identification number. The completeness of the match was confirmed by comparing maternal identity numbers.

A stepwise multiple logistic regression analysis was done with the Logist procedure of the SAS software to adjust for the effect of the studied independent variables. ${ }^{8}$ Asthma was used as the dependent variable. The independent variables were birth weight (in $500 \mathrm{~g}$ categories from $<2000 \mathrm{~g}-4500 \mathrm{~g}$ ), ethnic origin (according to paternal country of birth), area of residence (classified by municipal tax level), ${ }^{6}$ maternal age (as a continuous variable), paternal educational attainment (years of schooling) and birth order (categorised to avoid dubious assumptions about linearity). All variables that were significant $(p<0.05)$ were added to a model that contained the birth weight variable at the first step.

The results of the logistic regressions are presented as adjusted odds ratios with their $95 \%$ confidence intervals (CI). The estimates presented are based on the exclusion of cases with missing values $(1 \cdot 9 \%)$.

\section{Results}

The overall incidence of asthma in our study population at 17 years of age was $3 \cdot 7 \%$. Subjects whose birth weight was between $2000-2499 \mathrm{~g}$ had a significantly higher incidence of asthma. Other factors that were associated with a significantly increased risk of asthma included European or North American ethnic origin, being the first born, and having a well educated father (table 1). There was a significantly lower inci- 
dence of asthma among subjects who were of Asian origin, who were high in the birth order, and whose fathers were less well educated (table 1). Obesity and area of residence were not related to the incidence of asthma.

To estimate the risk of asthma associated with birth weight a multiple logistic regression analysis was used to control for the effects of confounding variables. All the variables listed in table 1 were analysed. The final model reached by the stepwise procedure included the birth weight variable and four confounding variables: birth order, paternal education, maternal age, and ethnic origin. Logistic analysis of these data confirmed that there was a highly significantly increased risk of asthma at 17 years of age for those with birth weights of less than $2500 \mathrm{~g}$ (table 2).

Table 1 Distribution of population characteristics and incidence of asthma at 17 years of age among 20312 male subjects born in ferusalem, 1967-71

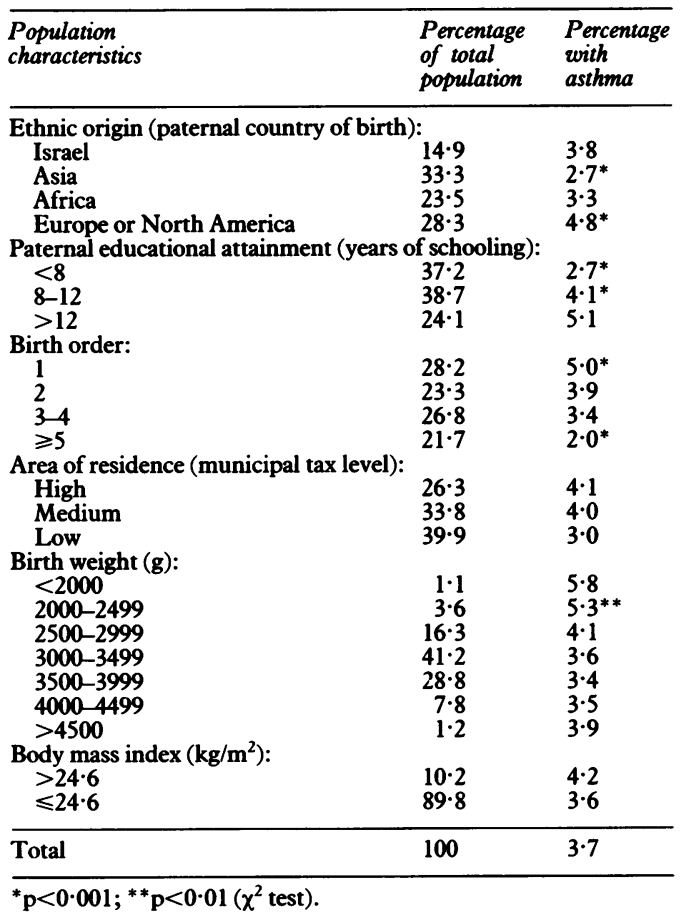

\section{Discussion}

The present study is the first to our knowledge that examines the incidence of asthma in association with birth weight in a large population for a period of 17 years. Low birth weight was associated with asthma diagnosed up to 17 years of age. Such an association has been suggested previously, ${ }^{9}$ and the need for long term follow up was stressed. ${ }^{10}$ Most previous studies have shown that small groups of infants who survive specific neonatal respiratory complications and treatments, including bronchopulmonary dysplasia, ${ }^{11} 12$ hyaline membrane disease, ${ }^{13-15}$ or artificial ventilation have reduced airway function. ${ }^{16-19}$ In some studies, however, impairment in lung function has been observed in healthy LBW infants as well. ${ }^{20}$ Furthermore, long term follow up studies extending to school age have shown that abnormal lung function is not unusual among LBW children. ${ }^{34} 171821$ The association between low birth weight and poor airway function is independent of neonatal respiratory illness, oxygen treatment, or mechanical ventilation. ${ }^{34}$ Perinatal factors, including the amount of respiratory support, were found to make only a small contribution to the reduction in airway function found in children of low birth weight at the ages of $7^{22}$ and $9^{23}$ years.

A number of possible explanations for the link between low birth weight and asthma have been proposed. The reduced airway function has been attributed to constitutional factors, prematurity itself, or other undetermined factors. ${ }^{23}$ The airway hyperactivity found at 7 and 12 years of age in prematurely born children without neonatal lung disease, led Bertrand $e t$ al to speculate that unexplained premature labour may share a common pathway with airway lability. ${ }^{24}$ In the present study we could not take into account the family history of asthma. Chan et $a l$, in a prospective study on a cohort of 7 year old children of low birth weight, found an increased prevalence of airway responsiveness to histamine that was significantly related to a history of asthma in siblings, ${ }^{25}$ but they were unable to confirm the hypothesis that maternal smooth muscle irrita-

Table 2 Adjusted odds ratios for asthma at 17 years of age by birth weight, ethnic origin, area of residence, maternal age, paternal education, and birth order for 20312 male subjects born in ferusalem, 1964-71

\begin{tabular}{|c|c|c|c|}
\hline Variable & No of subjects & Adjusted odds ratios & $\begin{array}{l}95 \% \text { confidence } \\
\text { intervals }\end{array}$ \\
\hline $\begin{array}{l}\text { Birth weight (g): } \\
<2000 \\
2000-2499 \\
2500-2999 \\
3000-3499^{*} \\
3500-3999 \\
4000-4499 \\
>4500\end{array}$ & $\begin{array}{r}223 \\
781 \\
3311 \\
8369 \\
5160 \\
1584 \\
244\end{array}$ & $\begin{array}{l}1.44 \\
1.49(p<0.001) \\
1.09 \\
1.00 \\
0.97 \\
1.11 \\
1.30\end{array}$ & $\begin{array}{l}(0.79 \text { to } 2.62) \\
(1.05 \text { to } 2.12) \\
(0.89 \text { to } 1.35) \\
(0.81 \text { to } 1.17) \\
(0.83 \text { to } 1.49) \\
(0.73 \text { to } 2.67)\end{array}$ \\
\hline $\begin{array}{l}\text { Birth order: } \\
1 \\
2^{*} \\
3-4 \\
\geqslant 5\end{array}$ & $\begin{array}{l}5727 \\
4733 \\
5444 \\
4408\end{array}$ & $\begin{array}{l}0.72(\mathrm{p}<0.001) \\
1.00 \\
0.58(\mathrm{p}<0.001) \\
0.33(\mathrm{p}<0.001)\end{array}$ & $\begin{array}{l}(0.59 \text { to } 0.89) \\
(0.47 \text { to } 0.73) \\
(0.24 \text { to } 0.45)\end{array}$ \\
\hline $\begin{array}{l}\text { Paternal education (years): } \\
<8 \\
8-12^{*} \\
>12\end{array}$ & $\begin{array}{l}7556 \\
7861 \\
4895\end{array}$ & $\begin{array}{l}t \\
1.00 \\
1.33(\mathrm{p}<0.001)\end{array}$ & $(1 \cdot 13$ to $1 \cdot 58)$ \\
\hline $\begin{array}{l}\text { Ethnic origin: } \\
\text { Israel* } \\
\text { Asia } \\
\text { Africa } \\
\text { Europe or North America }\end{array}$ & $\begin{array}{l}3027 \\
6764 \\
4773 \\
5748\end{array}$ & $\begin{array}{l}1.00 \\
0.81(p<0.05) \\
t\end{array}$ & 0.66 to 0.99 ) \\
\hline
\end{tabular}

${ }^{*}$ Reference group; tvariable not significant in the final logistic model. 
bility (uterine and bronchial) has a causative role in either the premature labour or in the subsequent airway hyper-responsiveness in the prematurely born infants.

The excess risk of asthma may also be the outcome of acute lower respiratory tract infections in infancy including bronchitis, bronchiolitis and pneumonia, ${ }^{26-28}$ which are known to be more common among LBW children. ${ }^{12}$ Asthma has also been related to other diseases of infancy including throat or ear infections, eczema, and allergic rhinitis, ${ }^{29}$ all reported more frequently among LBW infants. ${ }^{30}$

Area of residence, social class, and family size are associated with a history of upper ${ }^{31}$ and lower $^{32-35}$ respiratory tract infections. Because the incidence LBW infants is increased among families in low socioeconomic groups ${ }^{36}{ }^{37}$ poor environmental conditions may explain the observed link between LBW and asthma in childhood and adolescence. It is interesting to note that while Burr found that having more siblings increased the likelihood of prolonged colds, and of wheeze and nasal discharge. ${ }^{38}$ Strachan showed a strong inverse relationship between hay fever and the number of children in the household at the age of $11 .^{39}$ The present results show a decreased risk of asthma for children of high birth order, which accords with the atopic nature of the disease. The higher incidence of asthma in smaller households may be a possible explanation for the current increase in the prevelance of asthma. ${ }^{8} 3839$

Maternal smoking in pregnancy is a major determinant of birth weight, ${ }^{36} 40$ and its intrauterine effects may be related to lower respiratory tract illness in early life. ${ }^{41}$ Furthermore, LBW infants affected by maternal and environmental (passive) smoking antenatally are more likely to be exposed to tobacco smoke during childhood. ${ }^{42}$ This may lead to an increased incidence of respiratory illness ${ }^{43}$ and aggravation of asthma. ${ }^{38} 4445$ Data on the incidence of smoking among our sample was not available, but as adolescents born to mothers that smoke are more prone to do so themselves, they are also more likely to have been born with a lower birth weight and subsequently to have bronchial disease as a result of their smoking. Smoking by both the mothers and the subjects themselves may thus confound the association between low birth weight and asthma.

Birth weight could not be corrected for gestational age in the present sample, so it was not possible to find out if the increased risk of asthma was related to intrauterine growth retardation or immaturity. Nevertheless, low birth weight remains an important indicator of neonatal outcome.

In the present study, a large population from a geographically defined area was evaluated. The results may thus reflect the later effect of low birth weight on pulmonary function in relation to the incidence in our population. Population studies are important, as estimates of the incidence of asthma in childhood vary widely as a result of the different diagnostic labels given. ${ }^{46} 47$ Our findings indicate that LBW infants have an increased risk of asthma in childhood and adolescence. Further research is necessary to improve our understanding of the factors that predispose low birthweight infants to asthma in later life.

We acknowledge financial assistance from the Doron Foundation.

1 Vohr BR, Garcia Coll CT. Neurodevelopment and school performance of very low birthweight infants: a seven-year longitudinal study. Pediatrics 1985;76:345-50.

2 Lloyd BW, Wheldall K, Perks D. Controlled study of intelligence and school performance of very low-birth weight children from a defined geographical area. Dev Med Child Neurol 1988;30:36-42.

3 Chan KN, Noble-Jamieson CM, Elliman A, et al. Lung function in children of low birth weight. Arch Dis Child 1989; 64:1284-93

4 Chan KN, Elliman A, Bruyan E, Silverman M. Respiratory symptoms in children of low birth weight. Arch Dis Child 1989;64:1294-304.

5 Davies AM, Prywes R, Tzur B, et al. The Jerusalem Perinatal Study. 1. Design and organization of a continuing, community-based, record-linked survey. Isr $\mathcal{f} \mathrm{Med} S c i$ 1969;5:1095-101.

6 Harlap S, Davics AM, Grover NB, Prywes R. The Jerusalem Perinatal Study: the first decade 1964-1973. Isr f Med Sci 1977;13:1073-82.

7 Kark JD, Kedem R, Revach M. Medical examination of Israeli 17-year-olds before military service as a national resource for health information. Isr $\mathcal{F}$ Med Sci 1986;22: resource

8 SAS Institute Inc. SUGI supplemental library users' guide. Version 5. Cary: SAS Institute Inc, 1986:269-93.

9 Noble-Jamieson CM, Lukeman D, Silverman M, Davies PA. Low birth weight children at school age: neurological, Low birth weight children at school age: neurological,
psychological, and pulmonary function. Semin Perinatol psychological,
$1982 ; 6: 266-73$.

10 Davies PA. Follow up of low birthweight children. Arch Dis Child 1984;59:794-7.

1 Smyth JA, Tabachnik E, Duncan WJ, et al. Pulmonary function and bronchial hyperreactivity in long-term survivors of bronchopulmonary dysplasia. Pediatrics 1981;68:336-40.

12 Vohr BR, Bell EF, Oh W. Infants with bronchopulmonary dysplasia. Am f Dis Child 1982;136:443-7.

13 Heldt GP, MucIllory MB, Hansen TN, et al. Exercise performance of the survivors of hyaline membrane disease. f Pediatr 1980;96:995-9.

14 Stahlman M, Hedvall G, Lindstrom D, et al. Role of hyaline membrane disease in production of later childhood lung abnormalities. Pediatrics 1982;69:572-6.

15 Driscoll DJ, Kleinberg F, Heise CT, et al. Cardiorespiratory function in asymptomic survivors of neonatal respiratory distress syndrome. Mayo Clin Proc 1987;62:695-700.

16 Dinwiddie R, Mellor DH, Donaldson SHC, Tunstall ME, Russell G. Quality of survival after artificial ventilation of the newborn. Arch Dis Child 1974;49:703-10.

17 Borkenstein J, Borkenstein M, Rosegger H. Pulmonary function studies in long-term survivors with artificial ventilation in the neonatal period. Acta Paediatr Scand 1980;69: 159-63.

18 Riedel F. Long-term effects of artificial ventilation in neonates. Acta Paediatr Scand 1987;76:24-9.

9 Andreasson B, Lindroth M, Mortensson W, Svenningsen NW, Jonson B. Lung function eight years after neonatal ventilation. Arch Dis Child 1989;64:108-13.

20 Coates AL, Bergsteinsson H, Desmond K, et al. Long-term pulmonary sequelae of premature birth with and without
idiopathic respiratory distress syndrome. $\mathcal{f}$ Pediatr 1977; 90:611-6.

21 Mansell AL, Driscoll JM, James LS. Pulmonary follow-up of moderately low birthweight infants with and without respiratory distress syndrome. F Pediatr 1987;110:111-5.

22 Chan KN, Elliman A, Bryan E, Silverman M. Clinical significance of airway responsiveness in children of low birth weight. Pediatr Pulmonol 1989;7:251-8.

23 Chan KN, Wong YC, Silverman M. Relationship between infant lung mechanics and childhood lung function in children of very low birth weight. Pediatr Pulmonol 1990;8 74-81.

24 Bertrand JM, Riley SP, Popkin J, Coates AL. The long-term pulmonary sequelae of prematurity: the role of familial airway hyperreactivity and the respiratory distress syndrome. N Engl $\mathcal{F}$ Med 1985;312:742-5.

25 Chan KN, Noble-Jamieson CM, Elliman A, et al. Airway responsiveness in low birth weight children and their mothers. Arch Dis Child 1988;63:905-10.

26 Gurwitz D, Mindorff C, Levison H. Increased incidence of bronchial reactivity in children with a history of bronchitis. Pediatrics 1981;98:551-5.

27 Pullan CR, Hey EN. Wheezing, asthma, and pulmonary dysfunction 10 years after infection with respiratory syncytial virus in infancy. BMF 1982;284:1665-9.

28 Mok JYQ, Simpson $H$. Outcome for acute bronchitis, bronchiolitis, and pneumonia in infancy. Arch Dis Child 1984; 59:306-9.

29 Anderson HR, Bland JM, Patel S, Peckham C. The natural history of asthma in childhood. $\mathcal{J}$ Epidemiol Community 1986;40:121-9.

30 Overpeck MD, Moss AJ, Hoffman HJ, Hendershot GE. A comparison of the childhood health status of normal birth- 
weight and low birthweight infants. Public Health Rep 1989;104:58-70.

31 Burr ML, Miskelly FG, Butland BK, et al. Environmental factors and symptoms in infants at high risk of allergy. I Epidemiol Community Health 1989;43:125-32.

32 Holland WW, Halil T, Bennett AE, Elliott A. Factors influencing the onset of chronic respiratory disease. $B M \mathcal{F}$ 1969 ;ii:205-8.

33 Colley JRT, Douglas JWB, Reid DD. Respiratory disease in young adults: influence of early childhood lower respiratory tract illness social class, air pollution, and smoking. $B M \mathcal{F}$ 1973; iii: 195-8.

34 Barker DJP, Osmond C. Childhood respiratory infection and adult chronic bronchitis in England and Wales. BMF 1986; 293:1271-5.

35 Barker DJP, Osmond C, Law CM. The intrauterine and early postnatal origins of cardiovascular disease and chronic bronchitis. F Epidemiol Community Health 1989;43:237-40.

36 Kleinman JC, Madans JH. The effects of maternal smoking, physical stature, and educational attainment on the incidence of low birth weight. Am $\mathcal{F}$ Epidemiol 1985;121: 843-55.

37 Stein A, Campbell EA, Day A, McPherson K, Cooper PJ. Social adversity, low birth weight, and preterm delivery. $B M \mathcal{F}$ 1987;295:291-3.
38 Burr ML. Is asthma increasing? f Epidemiol Community Health 1987;41:185-9.

39 Strachan DP. Hay fever, hygiene, and household size. $B M \mathcal{F}$ 1989;299:1259-60.

40 Brooke OG, Anderson HR, Bland JM, et al. Effect on birth weight of smoking, alcohol, caffeine, socioeconomic factors, and psychosocial stress. BMF 1989;298:795-801.

41 Taylor B, Wadsworth J. Maternal smoking during pregnancy and lower respiratory tract illness in early life. Arch Dis Child 1987;62:786-91

42 Rubin DH, Krasilnikoff PA, Leventhal JM. Effect of passive smoking on birth weight. Lancet 1986;ii:415-17.

43 Harlap S, Davies AM. Infant admissions to hospital and

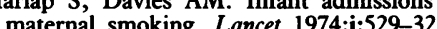

44 O'Connell EJ, Logan GB. Parental smoking in childhood Connell EJ, Logan GB. Parental s.
asthma. Ann Allergy 1974;32:142-5.

45 Weitzman M, Gortmaker S, Klein Walker D, Sobol A. Maternal smoking and childhood asthma. Pediatrics 1990; 85:505-11.

46 Lee DA, Winslow NR, Speight ANP, Hey EN. Prevalence and spectrum of asthma in childhood. $B M \mathcal{F}$ 1983;286: 1256-8.

47 Hill R, Williams J, Tattersfield A, Britton J. Change in use of asthma as a diagnostic label for wheezing illness in school children. BMF 1989;299:898.

Ban it!

The 'ban it' lobby are at it again, I see. Their target this time is toy balloons. Children sometimes inhale them, as they inhale many other things. A paper from Alberta (Ryan et al, American fournal of Diseases of Children 1990;144:1221-4) documents four deaths in Canada between 1983 and 1988. In the United States there were 121 childhood deaths from balloon inhalation between 1973 and 1988. The authors comment that 'protective efforts should be directed to a ban on this type of balloon'.

Most children who choke do so on food. Of those who choke on other things $90 \%$ do so on household articles, such as nails or bolts, and the remaining $10 \%$ inhale toys or other 'children's products'. Of this $10 \%, 43 \%$ involves balloons. Balloons are therefore 'the leading cause of paediatric choking deaths from children's products'.

Of course, if you go on subcategorising long enough almost anything can be shown to be the leading cause of something or other. Most of the road deaths in Britain not involving British, French, German, Swedish, or Italian cars probably involve Japanese cars which should, of course, therefore be banned.

I am $200 \%$ in favour of preventing childhood accidents but consider the pleasure given to so many children (and adults) by toy balloons. It is not possible to ban everything a child might put into his mouth or choke on. By all means let's educate people, children, and adults. Children choke; be careful. Don't leave things around or let them play with things they might choke on. Be careful with balloons; be careful with marbles; be careful with boiled sweets. Be careful, be careful, please be careful. But ban balloons? Must we? 